\title{
Establishing a tracking system in human resources department to improve the completeness of personnel files at a district hospital in Rwanda
}

\author{
Consolatrice Ibyimana ${ }^{1}$, Rex Wong*2, Eva Adomako ${ }^{2}$, Stephanie Lukas ${ }^{3}$, Francine Birungi ${ }^{4}$, Cyprien Munyanshongore ${ }^{4}$ \\ ${ }^{1}$ Nemba Hospital, Rwanda \\ ${ }^{2}$ Yale Global Health Leadership Institute, Yale University, United States \\ ${ }^{3}$ St. Louis College of Pharmacy, United States \\ ${ }^{4}$ School of Public Health, University of Rwanda, Rwanda
}

Received: June 23, 2016

DOI: $10.5430 /$ jha.v5n5p66
Accepted: July 22, 2016

Online Published: July 25, 2016

URL: http://dx.doi.org/10.5430/jha.v5n5p66

\begin{abstract}
Introduction: For decades, many low and mid income countries (LMIC) have invested significant effort to improve access to and quality of health care, with less attention paid to the non-clinical, administrative hospital management. Accordingly, a practical personnel filing system was designed and implemented to improve file management efficiency.

Methods: Setting: The quality improvement project took place in a rural hospital in Rwanda. Design: A pre- and post-intervention study design to assess the effect of the intervention between January 2015 and February 2016. File auditing and time study were conducted. Intervention: A custom-made computer database to manage documents in a personnel file, standardized follow up process and policy were created and implemented. Measures: The pre- and post-intervention completeness of all personnel file and the average time to identify the missing items in a personnel file were measured to evaluate the effect of the project.

Results: The completion rate of personnel files increased from $83 \%$ pre-intervention to $96 \%$ post-intervention. The average time to identify missing items significantly reduced from 6 minutes 30 seconds pre-intervention to 49.6 seconds $(p<.001)$.

Conclusions: This project demonstrates that quality improvement principles can help address administrative issues in a resourcechallenged setting. By utilizing available resources to implement an intervention that focused on creating an easy and efficient process, the personnel file completion rate has increased considerably and the time needed to identify missing items significantly decreased. The hospital should apply the same strategic problem solving methodology to conduct other quality improvement projects.
\end{abstract}

Key Words: Human resources management, Quality improvement, Low to middle income country, Resource-limited setting

\section{INTRODUCTION}

For decades, many low and mid income countries (LMIC) have invested significant effort to improve access to and quality of health care ${ }^{[1,2]}$ From medication supply chain management ${ }^{[3-7]}$ health workers programs ${ }^{[8-16]}$ from national health insurance systems ${ }^{[17-19]}$ to achieving hospital accreditation status, ${ }^{[20-22]}$ a great deal of the attention has been focused on the clinical aspects ${ }^{[23-29]}$ with less attention paid to the nonclinical, administrative hospital management. However, it's the personnel who keep the health systems running and represent the most expensive resource for an organization. ${ }^{[30,31]}$ that require proper management.

*Correspondence: Rex Wong; Email: rex.wong@ yale.edu; Address: Yale Global Health Leadership Institute, Yale University, United States. 
Personnel files provide a structure to inform hospital management of their staff's development and utilization to provide high quality health care effectively and efficiently. ${ }^{[30-32]}$ The importance of personnel file management usually pales when compared to other seemingly more critical clinicalcare-related issues, and as such, little attention is often paid to improving the efficiency of this administrative work. However, incomplete personnel files in hospitals could compromise staff and patient protection. Without proper personnel file management, appropriate and valid credentials and qualifications proving the healthcare professionals' competences would not be easily available. ${ }^{[33-37]}$ Well managed personnel files allow hospitals to produce accurate, easily accessible and organized information about employee compensation and benefits; performance including evaluations and any disciplinary action; and work history including hiring, promotions, transfers, retirements and terminations. This information is vital for both employee and the hospital and aids in the assurance that the hospital is staffed appropriately. ${ }^{[30,38-42]}$ Apart from being essential items in hospital management, proper personnel files are also essential for hospital accreditation. ${ }^{[43-45]}$ Rwanda's Ministry of Health, which aims to strengthen health systems by ensuring provision of high quality services, adopted a hospital accreditation system in 2006 as one of the main strategies to improve quality of care. ${ }^{[46]}$ All district hospitals in the country are currently under the process of accreditation. Common in many accreditation systems, human resources management is an important component in the accreditation standards.

However, as important as personnel files are, they are often incomplete. Common reasons causing poor personnel file management include lack of professionally trained file managers, insufficient investment in necessary hardware, and absence of clear policies or standardized work processes. ${ }^{[32]}$ Recognizing the widespread issue of incomplete personnel files in the human resources department (HRD) of a district hospital in Rwanda, the hospital saw an immediate need to address the problem. Accordingly, a practical personnel filing system was designed and implemented to improve file management efficiency. This paper aims to describe the process adopted by the hospital to improve personnel file completion rate.

\section{Methods}

\subsection{Setting}

The quality improvement project took place at Nemba District Hospital in the Northern Province of Rwanda. It has 169 beds and 155 staff. In December 2014, the hospital was assessed on their accreditation progression and the results indicated that incomplete personnel files was an important

Published by Sciedu Press issue. Many items in the personnel files were missing or out of date. Until that time, all personnel files were managed by the sole staff member working in the HRD who had a background in public health and received a few short courses in HR management. Before the intervention, a personnel file would be opened for a new employee; all required documents would be put in the file; and if there were any missing document, HR staff would follow up with the employee. Some documents required regular updating, they included annual performance evaluation, curriculum vitae, medical council certificates, or latest driver's license, however, it was the responsibility of each individual employee to provide the new documents to the HRD. While the HRD was to follow up with employees if documents were not received, there was no standardized follow-up process. The HRD staff member had to manually look through each personnel file in order to find out what was missing or expired. There were no policy or established schedule for this manual checking, and it was not done on a regular basis since the process was time consuming and the HRD had many competing tasks to perform. As a result, following up with the employees about their personnel files was not a priority; many documents were either missing or expired.

\subsection{Design and sample}

The study used a pre- and post-intervention study design to assess the effect of the intervention. The pre-intervention between January and November 2015 included a baseline assessment of the magnitude of the problem, root cause analysis and planning for the implementation. The intervention was conducted in December 2015. The post-intervention evaluation was conducted in February 2016. Approval to conduct this project was obtained from the hospital senior management. There were no conflicts of interest in this project.

For the personnel file completion rate, all of the hospital's 155 personnel files were audited in January 2015. The audit was conducted by a few authorized staff and the director of the HRD to ensure confidentiality. According to the accreditation and Rwanda's Ministry of Health requirements, each individual personnel file must contain the following 15 essential items: (1) job application letter, (2) signed job description, (3) results of the recruitment test, (4) copy of the identification card, (5) certified copies of obtained diplomas, (6) up-to-date copy of the driver's license, if required for the job, (7) employment certificates issued by the previous employers, if any, (8) training or advanced training certificates, if any, (9) appointment letter/employment contract, (10) curriculum vitae updated within the last year, (11) disciplinary sanctions (warning, suspension, etc.), if any, 
(12) correspondence between the hierarchy and the employee, if any, (13) passport photo, (14) performance assessment within the last year, and (15) council certificate (only for clinical staff). These 15 essential items in each personnel file were audited. An item was considered not to exist if it was missing or out of date. The completeness of personnel files were defined as a percentage of existing items over required items.

We also conducted a time study to measure the time the HR staff needed to identify if any of the 15 items were missing in a personnel file. We randomly selected 34 personnel files, and the time for the HR staff to complete the task for each file was recorded.

In the post-intervention evaluation, we used the same data collection process. All of the hospital's personnel files were audited; the files were mostly the same as in pre-intervention, except for the staff who were no longer working for the hospital and the newly hired since pre-intervention assessment. We also conducted a time study to determine the time it took for the HR staff to identify missing items in personnel files.

\subsection{Intervention}

A three-part tracking system was created for the HRD to improve the personnel file completeness: (1) creating a database to track all 15 essential items, (2) establishing a standardized follow up process for the HRD, and (3) creating a policy on the completion of the essential documents.

A database containing all 15 essential items that should be included in the personnel files was created using Microsoft Access and installed in the HRD computer. The tracking system had three main functions: data entry, update individual employee information and generating various summary reports.

When a new employee reports to the hospital, the employee information will be entered into the database, including the name, ID number and the availability of the 15 essential personnel file item. If an item required regular updates, or had expiration dates, like council certificate and driving license, the expiration date would also be entered into the system.

Once an employee's information was in the database, the HRD could enter any changes to the personnel file in order to update the status. For example, when an employee submits a new council certificate, the new expiration date would be entered in the system, and the certificate would be added to the staff member's personnel file. Once information was entered or updated, the database could generate various pre-set reports, providing information including a hospital summary report on the percentage of completeness for each item, items that had expired, and items that would expire within the next
2 months, as well as reports on what was missing/expired for any individual employees. The HRD could easily track the status of completeness of any personnel file.

A follow up schedule and standardized process was developed in collaboration with the HRD. The new process required the HRD to update the database immediately on receipt of a new document and generate a monthly hospital summary report on personnel file status on the $5^{\text {th }}$ of every month. After viewing the summary report the HRD would send written reminders to all concerned employees to update and complete their files by bringing the needed items to the HRD. A new hospital policy was created for the follow-up process. The names of the staff who did not comply for three consecutive months would be submitted to the director of administration for disciplinary measures.

\subsection{Data analysis}

The overall completeness of personnel file and each of the 15 essential items before and after the intervention were compiled and compared. Two independent sample $t$-tests were used to analyze the pre- and post-intervention average time needed for identifying the completeness of personnel file. The analysis was conducted using SPSS software v. 17.

\section{RESUlts}

All of the hospital's 155 personnel files were audited in preintervention. The overall completion rate in pre-intervention was $83 \%$. In the post-intervention period, due to personnel turnover, 152 files were audited. The overall completion rate in post-intervention was $96 \%$. This shows that our 3 step intervention helped increase the overall completion rate by $13 \%$, from $83 \%$ to $96 \%$ (see Table 1 ).

The three items most related to the improvement in the personnel file completion rate were: certified copies of diplomas ( $84 \%$ to $100 \%$ ); curriculum vitae within a year (6\% to $96 \%$ ); and annual evaluation within the last 12 months (0\% to $92 \%$ ). The council certificate only increased from $62 \%$ to $63 \%$ (see Table 1).

The average time to identify missing items in 34 personnel files reduced from 6 minutes 30 seconds pre-intervention to 49.6 seconds; the new system significantly decreased the average time for identifying missing items by 5 minutes and 40 seconds with $p<.001$ (see Table 2).

\section{Discussion}

Our project significantly improved the personnel file completion rate and reduced the time required to identify missing documents. The 10-month pre-intervention period included detail assessment, planning, creation of the database, and set- 
ting up the new work process. Apart from human resources and time investment, the project required no financial cost from the hospital. Our quality improvement project showed that a well-designed project can successfully improve completeness of personnel files with little investment from the hospital.

Table 1. Comparison of percentage of completeness pre- and post-intervention

\begin{tabular}{|c|c|c|c|c|c|c|c|c|}
\hline & & \multicolumn{3}{|c|}{ Pre } & \multicolumn{3}{|c|}{ Post } & \multirow{2}{*}{ Change } \\
\hline & & Required & Exist & $\%$ & Required & Exist & $\%$ & \\
\hline 1. & Job application letter & 155 & 155 & $100 \%$ & 152 & 152 & $100 \%$ & $0 \%$ \\
\hline 2. & Signed job description & 155 & 155 & $100 \%$ & 152 & 152 & $100 \%$ & $0 \%$ \\
\hline 3. & Results of the recruitment test & 155 & 155 & $100 \%$ & 152 & 152 & $100 \%$ & $0 \%$ \\
\hline 4. & Copy of the identification card & 155 & 155 & $100 \%$ & 152 & 152 & $100 \%$ & $0 \%$ \\
\hline 5. & Certified copies of obtained diplomas & 155 & 130 & $84 \%$ & 152 & 152 & $100 \%$ & $16 \%$ \\
\hline 6. & Up-to-date copy of driver's license, if required & 10 & 10 & $100 \%$ & 9 & 8 & $89 \%$ & $-11 \%$ \\
\hline 7. & Previous employment certificates, if any & 146 & 146 & $100 \%$ & 146 & 145 & $99 \%$ & $-1 \%$ \\
\hline 8. & Received training or advanced training certificates & 60 & 60 & $100 \%$ & 60 & 60 & $99 \%$ & $-1 \%$ \\
\hline 9. & Appointment Letter/updated contract & 155 & 155 & $100 \%$ & 152 & 152 & $100 \%$ & $0 \%$ \\
\hline 10. & Updated Curriculum Vitae within the last year & 155 & 10 & $6 \%$ & 152 & 152 & $96 \%$ & $90 \%$ \\
\hline 11. & Disciplinary sanctions (if any) & 75 & 75 & $100 \%$ & 85 & 85 & $100 \%$ & $0 \%$ \\
\hline 12. & Correspondence between hierarchy and employee & 155 & 155 & $100 \%$ & 152 & 152 & $100 \%$ & $0 \%$ \\
\hline 13. & Passport photo & 155 & 155 & $100 \%$ & 152 & 152 & $100 \%$ & $0 \%$ \\
\hline 14. & Annual Evaluation within the last 12 months & 155 & 0 & $0 \%$ & 152 & 140 & $92 \%$ & $92 \%$ \\
\hline 15. & Council certificate & 106 & 66 & $62 \%$ & 103 & 65 & $63 \%$ & $1 \%$ \\
\hline \multicolumn{2}{|c|}{ Overall completeness } & & & $83 \%$ & & & $96 \%$ & $13 \%$ \\
\hline
\end{tabular}

Table 2. Average time to look for missing items pre- and post-intervention

\begin{tabular}{lllll}
\hline & Pre & Post & Change & $\boldsymbol{p}$-value \\
\hline Sample $(\mathrm{N})$ & 34 & 34 & - & \\
Mean in second $(S D)$ & $390(74.22)$ & $49.6(20.01)$ & 340.4 & $<.001$ \\
\hline
\end{tabular}

The keys to the success of the project was the use of a strategic problem solving approach where a problem is addressed using very few financial resources. A working team was formed with the stakeholders, and collaboratively, the team defined the problem and assessed the situation to identify root causes. Understanding the gaps in the process allowed the team to create an intervention that was feasible to implement and cost effective.

The support from the hospital senior management team and the continuous commitment from the human resources manager were important. Clear directives from management allowed the staff to understand the importance of this project. The human resources staff took ownership of the project from the beginning, allowing an easy implementation and minimum resistance. Clear communication was also important. With a clearly defined, standardized process, the human resource staff could inform and remind staff regularly to submit their missing items. Understanding the importance of the new system, the Information Technology Department was committed to providing technical support to maintain the computer database system. While utilizing all existing available resources, the project cost the hospital no financial investment; this was critical to the feasibility and sustainabil- ity of the project.

The selected intervention addressed the gaps which were identified during assessment: (1) Creating a computer system that automatically generates reports decreased the time needed for the HR staff to identify missing items significantly; the computer system also helps minimize human errors when manually going through paperwork. The significant reduction of time means HR staff is more likely to follow up and sustain the new system; (2) Creating a standardized work process also increases the likelihood of following up. With a routine schedule, staff will be given reminders with sufficient time to submit their missing items.

Despite the initial successes, the project has several limitations. First, the study focused on addressing the internal issues related to tracking and reminding staff; however, there are some external factors that this project did not address. For example, clinical staff need to submit their Council Certificates which are issued by different professional councils. The hospital has no control over the timing in which the certificates are issued. As a result, the council certificate remained the item with the least completion rate. Second, the study had a relatively short follow-up time after implementation, so the long-term sustainability is unknown at this point. Longer term follow up is needed.

\section{Conclusions}

This project demonstrates that quality improvement principles can help address administrative issues in a resource- 
challenged setting. By utilizing available resources to implement an intervention that focused on creating an easy and efficient process, the personnel file completion rate has increased considerably and the time needed to identify missing items significantly decreased. The hospital should apply the same strategic problem solving methodology to conduct other quality improvement projects.

\section{CONFlicts OF InTEREST Disclosure}

The authors declare they have no conflicts of interest.

\section{REFERENCES}

[1] Chakkalakal RJ, Cherlin E, Thompson J, et al. Implementing clinical guidelines in low-income settings: A review of literature. Global Public Health. 2013 Aug 13; 8(7): 784-95. http://dx.doi.org/1 $0.1080 / 17441692.2013 .815794$

[2] Shaw C. Quality and Accreditation in Health Care Services: A Global Review. Evidence and Information for Policy, Department of Health Service Provision, World Health Organization; 2003.

[3] WHO. 2000. The World Health Report 2000 Health Systems: Improving performance. Geneva: World Health Organization Available from: http://deliver.jsi.com/dlvr_content/r esources/allpubs/countryreports/MW_DistDMPACommLev e.pdfAccessedonJuly2015

[4] DELIVER. 2011. Using Last Mile Distribution to Increase Access to Health Commodities. USAID I DELIVER PROJECT, Task Order 4. Available from: http://deliver.jsi.com/dlvr_content/r esources/allpubs/guidelines/UsinLastMileDist.pdf

[5] Bunde E, Kajawu L, Marufu C, et al. 2007. Zimbabwe: Delivery Team Topping Up (DTTU) System Assessment. Arlington, Va.: USAID I DELIVER PROJECT, Task Order 1. Available from: http: //deliver.jsi.com/dlvr_content/resources/allpubs/l ogisticsbriefs/ZM_MeasCostOptiHealCommDel.pdf

[6] DELIVER. 2007. Zimbabwe: Final Country Report. Arlington, Va.: DELIVER, for the U.S. Agency for International Development. Available from: http: //deliver.jsi.com/dlvr_content/resources/allpu bs/policypapers/DELIVER_FinalProjectReport.pdf

[7] Hasselberg E, Byington J. Supply chain models and considerations for community-based distribution programs: a program manager's guide. Arlington (VA): John Snow, Inc., for the Reproductive Health Supplies Coalition. 2010 Aug.

[8] Singh P, Sullivan S. One million community health workers: technical task force report. New York: Earth Institute at Columbia University. 2011; 304-10.

[9] Tulenko K, Mgedal S, Afzal MM, et al. Community health workers for universal health-care coverage: from fragmentation to synergy. Bulletin of the World Health Organization. 2013 Nov; 91(11): 847-52. http://dx.doi.org/10.2471/BLT.13.118745

[10] World Health Organization. Joint WH. Integrating community health workers in national health workforce plans. Geneva: WHO; 2010.

[11] Singh P, Sachs JD. 1 million community health workers in subSaharan Africa by 2015. The Lancet. 2013 Jul 27; 382(9889): 363-5

[12] Haines A, Sanders D, Lehmann U, et al. Achieving child survival goals: potential contribution of community health workers. The Lancet. 2007 Jun 29; 369(9579): 2121-31. http://dx . doi .org/1 $0.1016 / \mathrm{S} 0140-6736$ (07)60325-0

[13] Campbell J, Dussault G, Buchan J, et al. A universal truth: no health without a workforce. Geneva: World Health Organization. 2013 Available from: http://www . who.int/workforcealliance/kn owledge/resources/GHWA_AUniversalTruthReport.pdf
[14] Naimoli JF, Perry HB, Townsend JW, et al. Strategic partnering to improve community health worker programming and performance: features of a community-health system integrated approach. Human Resources for Health. 2015 Sep 1; 13(1): 46. PMid: 26323276. http://dx.doi.org/10.1186/s12960-015-0041-3

[15] Christopher JB, Le May A, Lewin S, et al. Thirty years after AlmaAta: a systematic review of the impact of community health workers delivering curative interventions against malaria, pneumonia and diarrhoea on child mortality and morbidity in sub-Saharan Africa. Hum Resour Health. 2011 Oct 24; 9(1): 27. PMid: 22024435. http://dx.doi.org/10.1186/1478-4491-9-27

[16] Swider SM. Outcome effectiveness of community health workers: an integrative literature review. Public Health Nursing. 2002 Jan 1; 19(1): 11-20. PMid: 11841678. http://dx.doi.org/10.1046/j $.1525-1446.2002 .19003 . \mathrm{x}$

[17] Mishra SR, Khanal P, Karki DK, et al. National health insurance policy in Nepal: challenges for implementation. Global Health Action. 2015; 8. http://dx.doi.org/10.3402/gha.v8. 28763

[18] Dalinjong PA, Laar AS. The national health insurance scheme: perceptions and experiences of health care providers and clients in two districts of Ghana. Health Economics Review. 2012 Jul 23; 2(1): 1. PMid: 22828034. http://dx.doi.org/10.1186/2191-1991-2 $-13$

[19] Lagomarsino G, Garabrant A, Adyas A, et al. Moving towards universal health coverage: health insurance reforms in nine developing countries in Africa and Asia. The Lancet. 2012 Sep 14; 380(9845): 933-43. http://dx.doi.org/10.1016/S0140-673 6(12) 61147-7

[20] Bradley E, Hartwig KA, Rowe LA, et al. Hospital quality improvement in Ethiopia: a partnership-mentoring model. International Journal for Quality in Health Care. 2008 Dec 1; 20(6): 392-9. PMid: 18784268. http://dx.doi.org/10.1093/intqhc/mzn042

[21] Towers AL. Clinical Documentation Improvement-A Physician Perspective. J AHIMA. 2013 Jul; 84(7): 34-41. PMid: 23926870.

[22] D'Amore JD, Sittig DF, Wright A, et al. The promise of the CCD: challenges and opportunity for quality improvement and population health. InAMIA Annu Symp Proc. 2011 Oct; 2011: 285-294.

[23] Robinson S, Pawelzik V, Megentta A, et al. A case study: Applying quality improvement methods to reduce pre-operative length of stay in a resource-constrained setting in Rwanda. Journal of Hospital Administration. 2015 Nov 5; 5(1): 41. http://dx. doi.org/10.54 30/jha.v5n1p41

[24] Budd A, Lukas S, Hogan U, et al. A Case Study and the Lessons Learned from In-House Alcohol Based Hand Sanitizer Production in a District Hospital in Rwanda. Journal of Service Science and Management. 2016 Mar 31; 9(02): 150. http://dx.doi.org/10. 4236/jssm. 2016.92019

[25] Atnafu A, Haile MD, Wong R, et al. Improving Adult ART Clinic Patient Waiting Time by Implementing an Appointment System at Gondar University Teaching Hospital, Northwest Ethiopia. Ad- 
vances in Public Health. 2015 Sep 21; 2015(1): 341-42. http: //dx.doi.org/10.1155/2015/892464

[26] Kmanzi J, Megentta A, Nsabiyumva W, et al. Improving Clinical Documentation through Monthly Audits in Butare Teaching Hospital, Rwanda. Journal of Service Science and Management. 2015 Nov 19; 8(06): 860. http://dx.doi.org/10.4236/jssm. 2015.86086

[27] Byiringiro JC, Wong R, Davis C, et al. Applying quality improvement principles to improve accident and emergency department overcrowding and flow in Rwanda: a case study. Journal of Hospital Administration. 2015 Jul 6; 4(5): 47. http://dx.doi.org/10. 54 30/jha.v4n5p47

[28] Wong R, Bradley EH. Developing patient registration and medical records management system in Ethiopia. International Journal for Quality in Health Care. 2009 Aug 1; 21(4): 253-8. PMid: 19574294. http://dx.doi.org/10.1093/intqhc/mzp026

[29] Wong R, Hathi S, Linnander EL, et al. Building hospital management capacity to improve patient flow for cardiac catheterization at a cardiovascular hospital in Egypt. Joint Commission journal on quality and patient safety/Joint Commission Resources. 2012 Apr; 38(4): 147.

[30] Cain P, Thurston A. Personnel Records: A Strategic Resource for Public Sector Management. A Research Report Submitted to ODA ESCOR, University College London; 1997 Mar.

[31] Michie S, West MA. Managing people and performance: an evidence based framework applied to health service organizations. International Journal of Management Reviews. 2004 Jun 1; 5(2): 91-111. http://dx.doi.org/10.1111/j.1460-8545.2004.00098.x

[32] Martino G, Kleiner BH. Personnel file management. Management Research News. 2000 Jul 1; 23(7/8): 49-52. http://dx.doi.org $/ 10.1108 / 01409170010782163$

[33] World Health Organization. The world health report 2000: health systems: improving performance. World Health Organization. 2000. Available from: http://www . who.int/whr/2000/en/

[34] Zurn P, Poz MRD, Stilwell B, et al. Imbalance in the health workforce. Human Resources for Health. 2004 Sep 17; 2(1): 13. PMid: 15377382. http://dx.doi.org/10.1186/1478-4491-2-13

[35] Rwanda Hospital Accreditation Standards. Second edition. Ministry of Health. October 2014. Available from: http: //www.moh.gov.rw/fileadmin/templates/Clinical/RWAN DA_HOSPITAL_ACCREDITATION_STANDARDS-SIGNED-1.pdf
[36] Alkhenizan A, Shaw C. Impact of accreditation on the quality of healthcare services: a systematic review of the literature. Annals of Saudi Medicine. 2011 Jul 1; 31(4): 407. PMid: 21808119. http://dx.doi.org/10.4103/0256-4947.83204

[37] Salmon JW, Heavens J, Lombard C, et al. The impact of accreditation on the quality of hospital care: KwaZulu-Natal province Republic of South Africa.

[38] Rawlins R. Hospital accreditation is important. BMJ: British Medical Journal. 2001 Mar 17; 322(7287): 674. PMid: 11291650.

[39] Alkhenizan A, Shaw C. Impact of accreditation on the quality of healthcare services: a systematic review of the literature. Annals of Saudi Medicine. 2011 Jul 1; 31(4): 407. PMid: 21808119 http://dx.doi.org/10.4103/0256-4947.83204

[40] Agarwal R. A guideline for quality accreditation in hospitals. 2010 Available from: http://www.qualitydigest.com/inside/t witter-ed/guideline-quality-accreditation-hospita ls.html

[41] Braithwaite J, Westbrook J, Johnston B, et al. Strengthening organizational performance through accreditation research-a framework for twelve interrelated studies: the ACCREDIT project study protocol. BMC Research Notes. 2011 Oct 9; 4(1): 390. PMid: 21981910 http://dx.doi.org/10.1186/1756-0500-4-390

[42] Joint Commission on Accreditation of Healthcare Organizations, Joint Commission Accreditation Hospital. Comprehensive Accreditation Manual for Hospitals: The Official Handbook: Camh. Joint Commission Resources. 2007.

[43] Hinchcliff R, Greenfield D, Moldovan M, et al. Narrative synthesis of health service accreditation literature. BMJ Quality \& Safety. 2012 Oct 4; 27(12): 979-91. PMid: 23038406. http://dx. doi .org/10. $1136 /$ bmjqs-2012-000852

[44] Shaw CD. Toolkit for accreditation programs. Melbourne: International Society for Quality in Health Care (ISQua). 2004.

[45] Montagu D. Accreditation and other external quality assessment systems for healthcare. DFID Health Systems Resource Centre Working Paper. 2003 May. Available from: http://www.dfidhealthrc.org/publications/health_ser vice_delivery/Accreditation.pdf

[46] Shaw CD. External quality mechanisms for health care: summary of the ExPeRT project on visitatie, accreditation, EFQM and ISO assessment in European Union countries. International journal for quality in health care. 2000 Jun 1; 12(3): 169-75. PMid: 10894187. http://dx.doi.org/10.1093/intqhc/12.3.169 